\title{
Model for the Performance of Airbreathing Pulse-Detonation Engines
}

\author{
E. Wintenberger* and J. E. Shepherd ${ }^{\dagger}$ \\ California Institute of Technology, Pasadena, California 91125
}

\begin{abstract}
A simplified flowpath analysis of a single-tube airbreathing pulse detonation engine is described. The configuration consists of a steady supersonic inlet, a large plenum, a valve, and a straight detonation tube (no exit nozzle). The interaction of the filling process with the detonation is studied, and it is shown how the flow in the plenum is coupled with the flow in the detonation tube. This coupling results in total pressure losses and pressure oscillations in the plenum caused by the unsteadiness of the flow. Moreover, the filling process generates a moving flow into which the detonation has to initiate and propagate. An analytical model is developed for predicting the flow and estimating performance based on an open-system control volume analysis and gasdynamics. The existing single-cycle impulse model is extended to include the effect of filling velocity on detonation tube impulse. Based on this, the engine thrust is found to be the sum of the contributions of detonation tube impulse, momentum, and pressure terms. Performance calculations for pulse detonation engines operating with stoichiometric hydrogen-air and JP10-air are presented and compared to the performance of the ideal ramjet over a range of Mach numbers.
\end{abstract}

\section{Nomenclature}

$A_{V}=$ valve and detonation tube cross-sectional area

$A_{0}=$ effective inlet capture area

$A_{2}=$ plenum cross-sectional area

$c \quad=$ speed of sound

$F \quad=$ thrust

$f \quad=$ fuel-air mass ratio

$g \quad=$ Earth's gravitational acceleration

$h \quad=$ enthalpy per unit mass

$h_{t} \quad=\quad$ stagnation enthalpy per unit mass

$I_{\mathrm{DT}}=$ detonation tube impulse

$I_{\mathrm{spf}} \quad=$ fuel-based specific impulse

$I_{\mathrm{spf}_{\mathrm{DT}}}=$ detonation tube fuel-based specific impulse

$L \quad=$ detonation tube length

$M \quad=$ Mach number

$M_{\text {fill }}=$ filling Mach number

$M_{S}=$ Mach number of the shock wave generated at valve opening in the burned gases

$\dot{m} \quad=$ mass flow rate

$\dot{m}_{F} \quad=$ average fuel mass flow rate

$P \quad=$ static pressure

$P_{R} \quad=$ initial pressure ratio across valve in numerical simulations of filling process

$P_{3} \quad=$ pressure on the closed valve during detonation and blowdown processes

$q \quad=$ heat release per unit mass

$R \quad=$ perfect gas constant

$T=$ static temperature

$t \quad=$ time

$t_{\mathrm{CJ}}=$ time taken by the detonation to reach the open end of the tube in the static case, $L / U_{\mathrm{CJ}}$

Presented as Paper 2003-4511 at the AIAA/ASME/SAE/ASEE 39th Joint Propulsion Conference and Exhibit, Huntsville, AL, 20-23 July 2003; received 13 October 2003; revision received 26 August 2005; accepted for publication 26 August 2005. Copyright (C) 2005 by California Institute of Technology. Published by the American Institute of Aeronautics and Astronautics, Inc., with permission. Copies of this paper may be made for personal or internal use, on condition that the copier pay the $\$ 10.00$ per-copy fee to the Copyright Clearance Center, Inc., 222 Rosewood Drive, Danvers, MA 01923; include the code 0748-4658/06 \$10.00 in correspondence with the CCC.

${ }^{*}$ Graduate Student, Graduate Aeronautical Laboratories; currently Thermal Engineer, General Electric Advanced Materials Quartz, Strongsville, OH 44149.

${ }^{\dagger}$ Professor, Graduate Aeronautical Laboratories. Member AIAA.

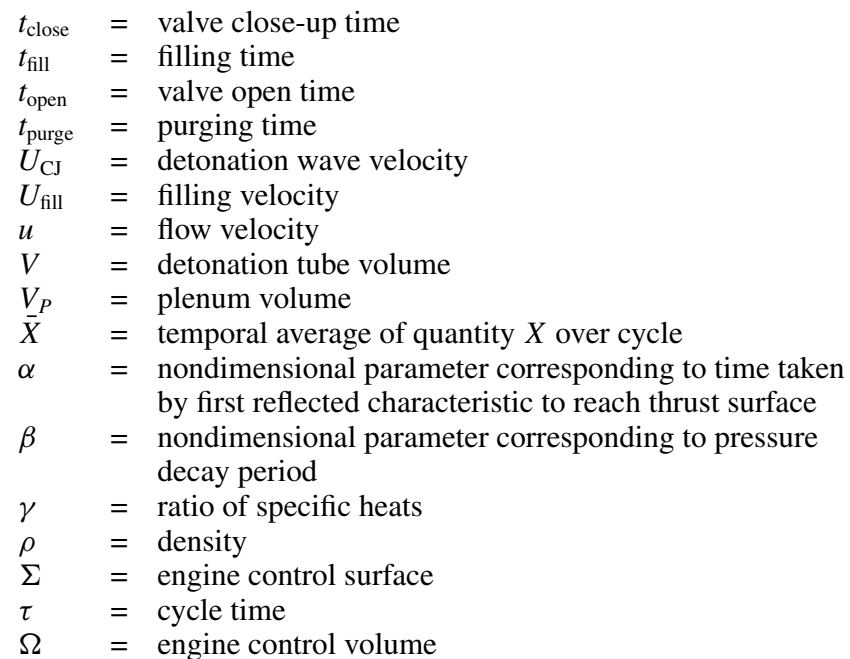

Subscripts

$a=$ air

$b \quad=$ burned gas

CJ = Chapman-Jouguet state

$\mathrm{DT}=$ detonation tube

$f \quad=$ state of detonation products at the end of blowdown process

$i=$ state of reactants before detonation initiation at the end of filling process

$P \quad=$ plenum conditions

$V \quad=$ valve plane

$0=$ freestream conditions

$2=$ state downstream of inlet

$3=$ state behind Taylor wave during detonation process

\section{Introduction}

$\mathbf{P}$ ULSE-DETONATION engines (PDEs) are propulsion systems based on the intermittent use of detonative combustion. A typical airbreathing PDE consists of an inlet, a series of valves, one or multiple detonation tubes, and an exit nozzle. Because of the intrinsically unsteady nature of the flowfield associated with the detonation process, it is difficult to evaluate the relative performance of airbreathing PDEs with respect to conventional steadyflow propulsion systems. This paper presents a performance model for airbreathing PDEs based on flowpath analysis. 
PDE performance analysis has followed several different approaches, starting with attempts to measure and model the static performance of single-cycle detonation tubes. Nicholls et al. ${ }^{1}$ pioneered the use of unsteady detonations for propulsion and carried out direct impulse measurements. More recently, several experimental, ${ }^{2-7}$ numerical, ${ }^{8-10}$ and modeling ${ }^{3,11-15}$ efforts have quantified the static single-cycle performance of a detonation tube. Although early numerical studies gave disparate and often contradictory values for performance parameters ${ }^{16}$ there is now substantial agreement, ${ }^{17,18}$ between numerical simulations and experimental measurements for selected mixtures.

In parallel, researchers have also experimentally investigated the static multicycle performance of single $\mathrm{e}^{3,19-22}$ and multiple ${ }^{23,24}$ detonation tubes. Although there is good agreement between some experimental multicycle data ${ }^{23,25}$ and single-cycle estimates, ${ }^{13}$ numerical simulations ${ }^{26}$ also showed that the multicycle performance can be substantially different from the single-cycle performance. Fuel injection, ignition, and refilling strategies, as well as the assumptions made for detonation initiation, ${ }^{17,22,26}$ play a crucial role in estimating the multicycle performance.

Although PDE static performance has been studied extensively, few efforts have focused on estimating the performance of an airbreathing PDE. The difficulties associated with coupling the inlet flow to the unsteady flow inside the detonation tube(s) and the interaction of the detonation wave and the subsequent unsteady flow with an exit nozzle are two significant modeling challenges. Paxson ${ }^{27}$ has carried out unsteady, one-dimensional computations and represented the results in terms of a performance map in total-pressuretotal-temperature coordinates. This methodology has been used to compute specific impulse and make comparisons to idealized ramjet and turbojet performance over a range of flight Mach numbers.

Bratkovich and Bussing ${ }^{28}$ presented a performance model for airbreathing PDEs that considers contributions from an inlet, a mixer, a combustor, and a nozzle. Kaemming ${ }^{29}$ conducted a mission analysis showing that an airbreathing PDE can present performance advantages over the turboramjet without providing any absolute performance values. Because of the proprietary nature of the work and the lack of details about these commercial models, ${ }^{28,29}$ the accuracy of these performance predictions is difficult to assess.

Wu et al.$^{30}$ have presented what is, so far, the most comprehensive system performance analysis for an airbreathing PDE. Their work is based on a modular approach, including supersonic inlet dynamics and detonation in single and multiple tubes. They carried out detailed numerical simulations for a hydrogen-fueled airbreathing PDE flying at $9.3 \mathrm{~km}$ altitude and a Mach number of 2.1. A series of parametric studies showed that the system performance decreased with increasing ignition delay and increasing refilling period for a fixed blowdown time. Investigations of nozzle design concluded that a limited performance gain was obtained for nonchoked nozzles, but that choked converging-diverging nozzles could considerably improve performance. Maximum fuel-based specific impulses on the order of $3500 \mathrm{~s}$ were obtained for stoichiometric hydrogen-air. More recently, Ma et al. ${ }^{31,32}$ presented numerical results showing the thrust chamber dynamics of single- and multiple-tube PDEs. They showed that the multiple-tube design improves the performance by reducing the degree of unsteadiness in the flow. Specific impulses as high as $3800 \mathrm{~s}$ at a flight Mach number of 2.1 were obtained with a single converging-diverging exit nozzle.

Other PDE performance estimates have been based on thermodynamic cycle analysis. Heiser and $\operatorname{Pratt}^{33}$ proposed a thermodynamic cycle based on the Zel'dovich-von Neumann-Döring (ZND) model of detonation and used the entropy method ${ }^{34}$ to predict performance. The constant volume combustion cycle has also been used as a surrogate for the detonation cycle. ${ }^{35,36}$ Performance models based on gasdynamics have been proposed. Talley and $\mathrm{Coy}^{37} \mathrm{de}-$ veloped a blowdown model assuming quasi-steady isentropic onedimensional nozzle flow following constant volume combustion. The performance results were compared to constant pressure propulsion devices. Harris et al. ${ }^{38}$ evaluated the respective performance of zero-, one-, and two-dimensional models for the PDE cycle and concluded that Talley and Coy's model ${ }^{37}$ offers a good approxima-

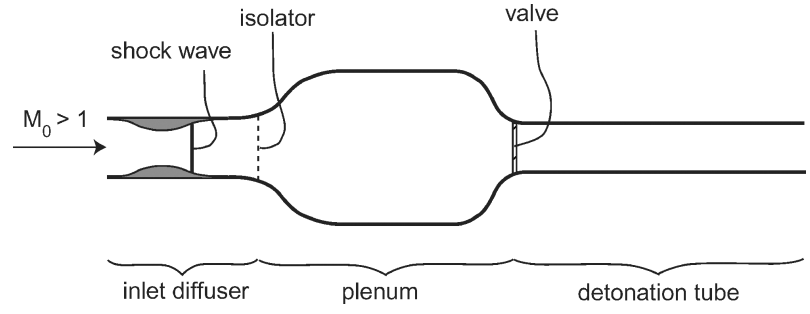

Fig. 1 Schematic of single-tube PDE.

tion of the time-averaged performance. Harris et al. ${ }^{39,40}$ have further developed their models and have performed comparisons with twodimensional numerical simulations.

Our goal is to develop a complete flowpath-based analysis of an airbreathing PDE that can be used to carry out parametric studies of performance without elaborate computational fluid dynamics simulations for each case. Building on previous work ${ }^{13}$ with a singlecycle detonation tube, we have developed an analytical model that takes into account all of the major engine components (except an exhaust nozzle) and their coupling. Our model is based on a fully unsteady one-dimensional control volume analysis of a single-tube airbreathing PDE. The performance of the airbreathing PDE is calculated from the conservation equations averaged over a cycle of operation. We compare the results with a conventional propulsion system, the ideal ramjet, at various operating conditions.

\section{Single-Tube Airbreathing PDE}

We consider a supersonic single-tube airbreathing PDE that consists of an inlet, a plenum, a valve, and a straight detonation tube. A schematic is given in Fig. 1. We assume a steady inlet because of its well-known performance characteristics. Installing a steady inlet in an unsteady airbreathing engine is possible as long as quasi-steady flow downstream of the inlet is achieved by one of two ways. The first way is to use multiple detonation tubes operating out of phase so that the flow upstream of the detonation tubes decouples from the unsteady flow inside the tubes, becoming quasi steady. The second way is to use a plenum downstream of the inlet that is large enough to dampen pressure transients generated by the valve operation. ${ }^{35}$ This second approach increases the engine total volume and may not be practical, but we adopt it in our one-dimensional modeling due to its simplicity. Other types of inlets for PDEs include unsteady valveless $s^{20,34,41}$ and valved ${ }^{34,35}$ inlets such as those used in pulsejet applications.

The steady inlet is separated from the plenum by an isolator (a grid or screen similar to what is used in ramjets). Flow perturbations generated by combustion or valve motion are assumed to be isolated within the plenum, and the inlet flow is unaffected. The valve is located at the upstream end of the detonation tube, separating it from the plenum. We assume that the valve opens and closes instantaneously. Although there are transients associated with finite opening and closing times, they must be modeled by more complex multidimensional numerical simulations and are outside the scope of this one-dimensional model. The fuel injection system is located downstream of the valve. Fuel is injected only during the filling process and is assumed to mix instantaneously with the flowing air. The effect of exit nozzles on detonation tube performance is not considered in this study, and the detonation tube is assumed to be straight.

\section{Control Volume Analysis}

The performance is determined by performing an unsteady opensystem control volume analysis. The control volume $\Omega$ (Fig. 2) is stationary with respect to the engine. The engine is attached to the vehicle through a structural support. The control surface $\Sigma$ passes through the engine valve plane and encompasses the detonation tube, extending far upstream of the inlet plane. The side surfaces are parallel to the freestream velocity. We consider the equations for mass, momentum, and energy for this control volume; see Wintenberger ${ }^{42}$ for details of the derivations. 


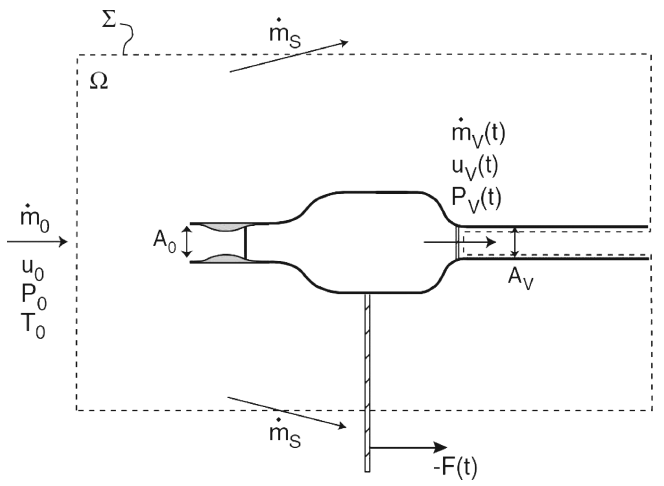

Fig. 2 Control volume used for analysis of single-tube PDE.

\section{Mass Conservation}

There is temporary mass storage through a cycle, but the average mass storage must equal zero for cyclic operation. We integrate the mass conservation equation between the inlet and the valve plane over a cycle to obtain

$$
\int_{0}^{\tau} \dot{m}_{V}(t) \mathrm{d} t=\tau \dot{m}_{0}
$$

\section{Momentum Conservation}

The forces to consider in the momentum equation are the pressure forces and the reaction to the thrust carried through the structural support. If we assume that the top and bottom sides of the control volume are sufficiently distant from the engine, then the flow crosses them with an essentially undisturbed velocity component in the flight direction. Using the continuity equation, we obtain an expression for the instantaneous thrust ${ }^{42}$

$$
F(t)=\dot{m}_{V}(t) u_{V}(t)-\dot{m}_{0} u_{0}+A_{V}\left(P_{V}(t)-P_{0}\right)+\frac{\mathrm{d}}{\mathrm{d} t} \int_{\Omega} \rho u \mathrm{~d} V
$$

The last term represents the unsteady variation of momentum inside the control volume.

\section{Energy Conservation}

In the absence of body forces and heat release (which occurs inside the detonation tube located outside our control volume), the energy equation can be simplified using the continuity equation and integrated over a cycle to yield ${ }^{42}$

$$
\int_{o}^{\tau} \dot{m}_{V}(t) h_{t V}(t) \mathrm{d} t=\tau \dot{m}_{0} h_{t 0}
$$

Because there is no average energy storage in the control volume in steady flight, the energy conservation equation requires the cycle average flux of stagnation enthalpy to be the same at the inlet and the valve plane.

\section{Thrust Calculation}

The average thrust is calculated by integrating Eq. (2) over a complete cycle. During steady flight, the total momentum in the control volume has a periodic behavior, and so the unsteady term vanishes when averaged over one period. The only situation in which the mass, momentum, and energy storage terms lead to nonzero cycleaveraged contributions are during unsteady flight conditions such as acceleration or deceleration. For this study, we restrict ourselves to performance calculations during steady flight conditions.

During a cycle, the valve is closed from time 0 to $t_{\text {close }}$ and open from $t_{\text {close }}$ to $\tau$. Introducing the detonation tube impulse $I_{\mathrm{DT}}$ generated by the detonation and blowdown processes,

$$
\int_{0}^{t_{\text {close }}} A_{V}\left(P_{V}(t)-P_{0}\right) \mathrm{d} t=I_{\mathrm{DT}}
$$

the average thrust is given by ${ }^{42}$

$$
\begin{aligned}
\bar{F}= & \frac{1}{\tau} I_{\mathrm{DT}}+\frac{1}{\tau} \int_{t_{\text {close }}}^{\tau} \dot{m}_{V}(t) u_{V}(t) \mathrm{d} t \\
& +\frac{1}{\tau} \int_{t_{\text {close }}}^{\tau} A_{V}\left(P_{V}(t)-P_{0}\right) \mathrm{d} t-\dot{m}_{0} u_{0}
\end{aligned}
$$

Note that the integration limits in Eqs. (4) and (5) are different. The average thrust is the sum of contributions from the detonation tube impulse, the momentum and pressure at the valve plane during the open part of the cycle, and the ram momentum. To evaluate this thrust, we need an estimate of the detonation tube impulse and of the momentum and pressure contributions at the valve plane during the part of the cycle when the valve is open. These terms have to be estimated by modeling the gasdynamics of the filling and detonation process.

\section{Detonation Tube Dynamics}

To estimate the different terms in the PDE thrust equation (5), we consider the dynamics of the detonation tube during one cycle. The parts of the cycle are shown in Fig. 3: In Fig. 3a the detonation is initiated at the closed end of the tube. In Fig. $3 b$ the detonation propagates toward the open end. In Fig. $3 \mathrm{c}$ the detonation diffracts outside as a decaying shock, and a reflected expansion wave propagates to the closed end, starting the blowdown process. In Fig. 3d at the end of the blowdown process, the tube contains burned products at rest. In Fig. 3e the purging/filling process is triggered by the opening of the valve, sending a shock wave in the burned gases, followed by the air-products contact surface. In Fig. $3 \mathrm{f}$ a volume of air is injected before the reactants for purging. In Fig. $3 g$ the purging air is pushed out of the tube by the reactants. In Fig. $3 \mathrm{~h}$ the reactants eventually fill the tube completely, and the valve is closed. The detonation/blowdown process occurs when the valve is closed (from 0 to $t_{\text {close }}$ ), and the purging and filling processes occur when the valve is open (from $t_{\text {close }}$ to $\tau$ ). The cycle time is the sum of the valve close and open times, the latter being the sum of the fill and purging times,

$$
\tau=t_{\text {close }}+t_{\text {open }}=t_{\text {close }}+t_{\text {fill }}+t_{\text {purge }}
$$

Experiments have shown that purging the burned gases (usually with air) is necessary to avoid preignition of the fresh mixture before the

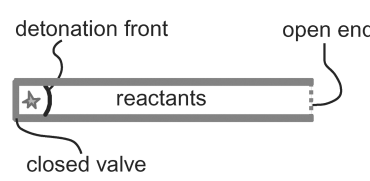

$$
\text { a) }
$$

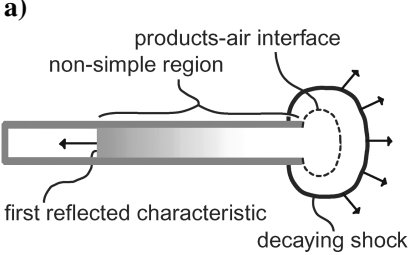

c)

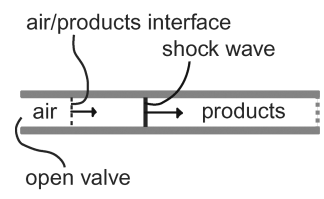

e)

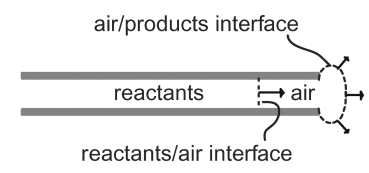

g)

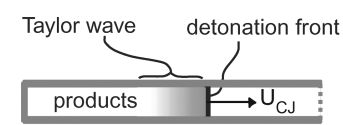

b)
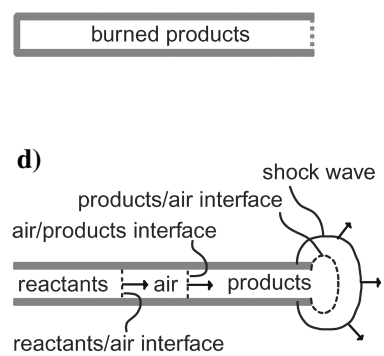

f)

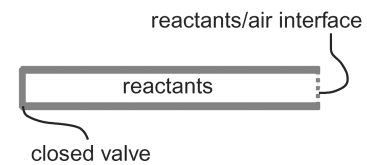

h)
Fig. 3 PDE cycle schematic for single detonation tube. 
detonation initiation. Because the air entering the plenum is decelerated and compressed through the inlet due to the ram effect, the plenum acts as a high-pressure air reservoir that periodically fills the detonation tube. Although the unsteady flow in the detonation tube is complex and involves many wave interactions, the main physical processes occurring during a cycle have been well documented in previous studies.

\section{Detonation/Blowdown Process}

The specific gasdynamics during this process were studied in detail by Wintenberger et al. ${ }^{13}$ for a static detonation tube. It was shown that as the detonation exits the tube, a reflected wave, typically an expansion, propagates back toward the closed valve. After interacting with the Taylor wave, this reflected expansion accelerates the fluid toward the tube's open end and decreases the pressure at the closed end of the tube. The pressure inside the tube typically decreases below the ambient pressure ${ }^{3}$ at the end of the blowdown process before returning to ambient pressure after about $20 t_{\mathrm{CJ}}$. This suggests that the valve for a given tube must be closed for at least $10 t_{\mathrm{CJ}}$ to maximize the impulse per cycle.

In an airbreathing PDE, the flow in the detonation tube differs from the static case because of the interaction between the detonation and filling processes. Closing the valve sends an expansion wave through the tube to decelerate the flow created by the filling process. This expansion wave will be overtaken within the tube by a detonation that is initiated immediately after valve closing. After this interaction, the detonation will propagate into the uniform flow produced by the filling process. The thrust for this situation will be different from the case of a detonation propagating into a stationary mixture but can be calculated if we assume ideal valve closing and detonation initiation.

\section{Purging/Filling Process}

At the end of the detonation/blowdown process, the valve at the upstream end of the tube opens instantaneously. This valve separates high-pressure air that was compressed through the inlet and burned gases at ambient pressure and elevated temperature. Opening the valve causes the high-pressure air to expand into the detonation tube. A shock wave is generated and propagates into the detonation tube, followed by a contact surface between the fresh air and the burned products. The fuel-air mixture is injected after a purging volume of air, whose role is to prevent preignition of the fresh mixture.

We analyzed the problem numerically with AMRITA. ${ }^{43}$ The simulations used the non-reactive Euler equations in an axisymmetric domain with a Kappa-MUSCL-HLLE solver. The configuration tested, similar to that of Fig. 1, consists of a plenum connected by a smooth area change to a straight tube open to a half-space. Two levels of adaptive mesh refinement with a factor of three in each direction were used; the finest grid is equivalent to a uniform mesh of about 140,000 points. The domain used to simulate the atmosphere was large enough so that any disturbances reflected back from the extrapolation boundary conditions did not influence the results. The simulations were started with high-pressure air in the plenum at conditions given by $P_{P} / P_{0}=P_{R}$ and $T_{P} / T_{0}=P_{R}^{(\gamma-1) / \gamma}$. The burned gases in the tube were at pressure $P_{0}$ and elevated temperature $T_{f}=7.69 T_{0}$ representative of the burned gas temperature at the end of the blowdown process. The air in the freestream region outside the detonation tube is at a static pressure $P_{0}$ and temperature $T_{0}$.

These numerical simulations, described in more detail by Wintenberger, ${ }^{42}$ lead to two main conclusions. First, they show that the initial flow and subsequent wave interactions inside the tube are essentially one-dimensional. Multidimensional effects are observed only within one tube diameter of the tube exit, just after the exhaust of the incident shock. Second, at valve opening, an unsteady expansion wave propagates upstream of the valve inside the plenum, setting up a quasi-steady expansion of the plenum air into the detonation tube. If the initial pressure difference across the valve is sufficiently large, an unsteady expansion will be set up within the tube. These expansion waves are crucial to the filling process and states created behind the subsequent detonation.

\section{Modeling of Filling Process}

The filling process is critical because it determines the momentum and pressure contributions at the valve plane, which are necessary to compute the thrust [Eq. (5)]. Moreover, it also determines the conditions in the tube before detonation initiation, necessary to predict the detonation tube impulse accurately. Based on our numerical simulations, we model the quantities at the valve plane with constant values during the filling process. This section discusses our approach, explains how these values are calculated, and compares them with the results of the numerical simulations.

\section{Plenum/Detonation Tube Coupling}

The average plenum conditions can be estimated by analyzing the control volume shown in Fig. 4. The cycle time is assumed to be much larger than the characteristic acoustic transit time in the plenum, and so the plenum properties are assumed to be spatially uniform. The plenum has a constant incoming mass flow rate and a nonzero outgoing mass flow rate when the valve is open. The plenum cross section is much larger than the inlet, and the average flow velocity is very subsonic. We average the mass, momentum, and energy conservation equations ${ }^{42}$ for the control volume $V_{P}$ defined in Fig. 4,

$$
\begin{aligned}
& \overline{\dot{m}_{V}(t)}=\dot{m}_{0} \\
& \overline{\dot{m}_{V}(t) u_{V}(t)}=A_{2} P_{t 2}-A_{V} \overline{P_{V}(t)}+\left(A_{V}-A_{2}\right) \overline{P_{P}(t)} \\
& \overline{\dot{m}_{V}(t) h_{t V}(t)}=\dot{m}_{0} h_{t 2}
\end{aligned}
$$

where the overbar indicates temporal averaging over a cycle.

The properties at the valve plane are modeled as piecewiseconstant functions of time. The velocity $u_{V}(t)$ and mass flow rate $\dot{m}_{V}(t)$ are equal to zero when the valve is closed and take on constant values when the valve is open. When it is assumed that the plenum volume is much larger than the detonation tube volume, the plenum pressure will be approximately constant throughout a cycle. The pressure at the valve plane equals the average plenum pressure except when the valve is open, in which case its value is determined from Eq. (8). Similarly, the total enthalpy at the valve plane equals the average plenum total enthalpy $\overline{h_{t P}}$ when the valve is closed, but, according to Eq. (9), the total enthalpy has to be conserved between the inlet and the valve plane so that $h_{t V}=h_{t 2}$ when the valve is open. The behavior of the pressure and mass flow rate at the valve plane through a cycle is shown schematically in Fig. 5.

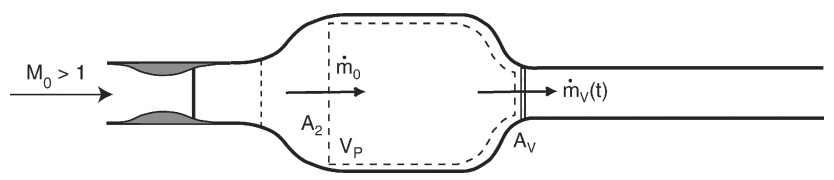

Fig. 4 Control volume $V_{P}$ used for analysis of flow in plenum.

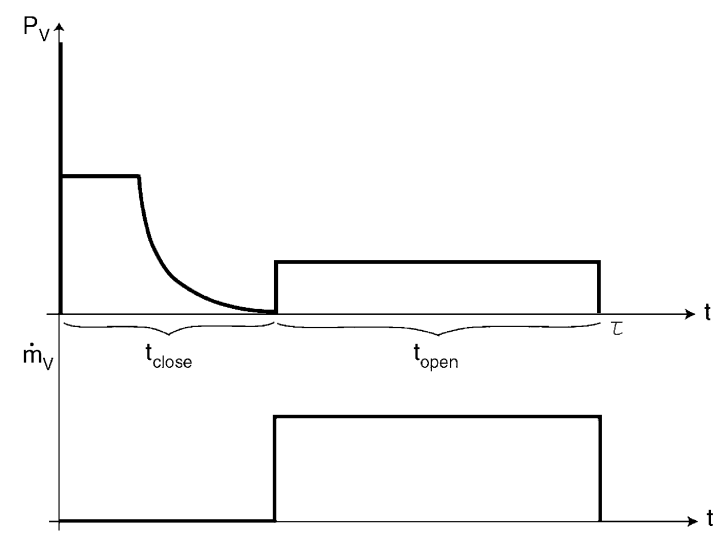

Fig. 5 Assumed time dependence of pressure and flow velocity at valve plane during cycle. 
The average conditions in the plenum are evaluated by considering the flow in the detonation tube when the valve is open. Because the valve plane corresponds to a geometrical throat, either sonic or subsonic flow at the valve plane may exist.

\section{Sonic Flow at Valve Plane}

When the valve opens, the unsteady expansion propagating upstream sets up a quasi-steady expansion through the area change between the plenum and the detonation tube and decays when propagating through the area change. We assume that its propagation time through the area change is much smaller than the time necessary to fill the detonation tube, and we neglect this initial transient.

The flow at the valve plane is sonic for sufficiently large values of the initial pressure ratio across the valve plane. The flow configuration, shown in Fig. 6, consists of a left-facing unsteady expansion in the plenum, a steady expansion through the area change, and an unsteady expansion between the valve plane and the fresh-airburned-gases contact surface following a right-facing shock wave propagating in the tube. This flow configuration is identical to that encountered in shock tubes with positive chambrage. ${ }^{44}$ The unsteady expansion in the plenum is very weak after its propagation through the area change, and we neglect it based on the assumption of a large area ratio between the plenum and the valve. ${ }^{42}$ The unsteady expansion in the tube accelerates the flow from sonic at the valve plane to supersonic behind the contact surface and decouples the plenum flow from the flow in the detonation tube. The interactions of the shock wave with the open end and any subsequent reflected waves are ignored. These assumptions are discussed further with respect to the results of numerical simulations of the filling process.

The flow in the detonation tube is calculated by matching pressure and velocity across the contact surface and solving for the shock

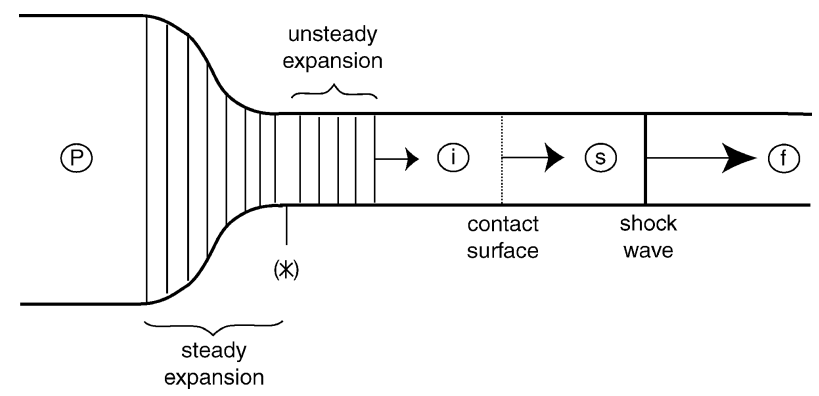

Fig. 6 Flow configuration used to model filling process in case of sonic flow at valve plane: ${ }^{*}$, valve plane.
Mach number, ${ }^{44}$

$\frac{\overline{P_{P}}}{P_{0}}=$

$$
\frac{1+\left[2 \gamma_{b} /\left(\gamma_{b}+1\right)\right]\left(M_{S}^{2}-1\right)}{\left\{\sqrt{\left(\gamma_{a}+1\right) / 2}-\left[\left(\gamma_{a}-1\right) /\left(\gamma_{b}+1\right)\right]\left(c_{f} / \overline{c_{P}}\right)\left(M_{S}-1 / M_{S}\right)\right\}^{2 \gamma_{a} /\left(\gamma_{a}-1\right)}}
$$

\section{Subsonic Flow at Valve Plane}

For sufficiently small values of the initial pressure ratio across the valve plane $\left\{\overline{P_{P}} / P_{V}<\left[\left(\gamma_{a}+1\right) / 2\right]^{\gamma_{a} /\left(\gamma_{a}-1\right)}\right\}$, the flow is subsonic at the valve plane without the unsteady expansion in the detonation tube shown in Fig. 6 . The velocity at the valve plane is equal to the postshock velocity in the burned gases. Because the filling process is modeled with a steady expansion between the plenum and the valve plane, the average enthalpy in the plenum can be estimated as the total enthalpy downstream of the inlet $\overline{h_{P}} \approx h_{t 2}$. As in the sonic flow case, the flow is solved by matching pressure and velocity across the contact surface, ${ }^{42}$

$$
\begin{aligned}
& \overline{P_{P}}= \\
& P_{0} \frac{1+\left[2 \gamma_{b} /\left(\gamma_{b}+1\right)\right]\left(M_{S}^{2}-1\right)}{\left\{1-\left[2\left(\gamma_{a}-1\right) /\left(\gamma_{b}+1\right)^{2}\right]\left(c_{f} / \overline{c_{P}}\right)^{2}\left(M_{S}-1 / M_{S}\right)^{2}\right\}^{\gamma_{b} /\left(\gamma_{b}-1\right)}}
\end{aligned}
$$

\section{Results and Comparison with Numerical Simulations}

The model predictions of the filling process are compared with the results of the numerical simulations described earlier. The valve plane velocity and pressure were calculated from the twodimensional simulations by spatially and temporally averaging these quantities along the valve plane. The average filling velocity was calculated as the average velocity of the inlet-air-burned-gas contact surface between the valve plane and the tube exit. These quantities, along with the pressure at the valve plane, are shown in Fig. 7 as a function of the initial pressure ratio $P_{R}$ for both model and simulations.

According to our one-dimensional model, the flow at the valve plane is expected to be sonic above a critical pressure ratio equal to 3.19. For pressure ratios lower than this value, the velocity at the valve plane is equal to the velocity of the contact surface: $u_{V}=U_{\text {fill }}$. For pressure ratios higher than this value, the flow configuration is that of Fig. 6; the flow is sonic at the valve plane and an unsteady expansion accelerates the flow to supersonic downstream of the valve plane. For this case, the values of the velocity at the valve plane (equal to the speed of sound) and the filling velocity (equal to the postshock velocity) are different. The two curves in Fig. 7 correspond to these two cases.
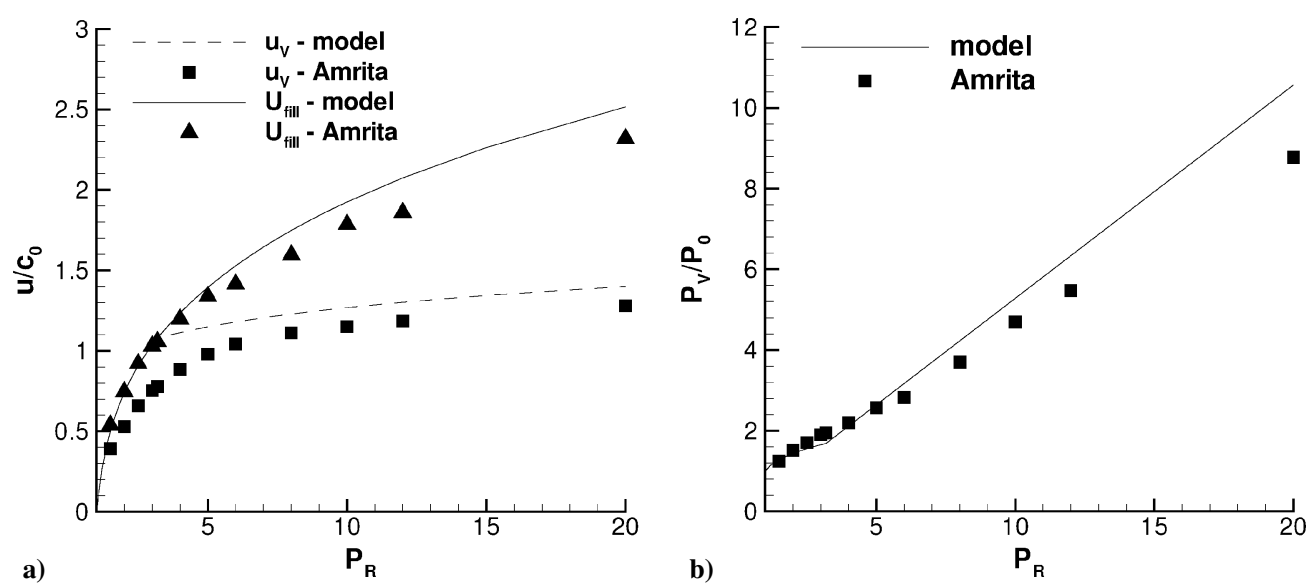

Fig. 7 Comparison of a) model predictions and b) numerical simulations for velocity at valve plane, average filling velocity, and pressure at valve plane: $T_{f} / T_{0}=7.69$ and $\gamma=1.4$. 
The model predictions for the filling velocity and the pressure at the valve plane are in reasonable agreement with the results of the numerical simulations, with a maximum deviation of 11 and $20 \%$, respectively. The model predictions for the velocity at the valve plane are systematically higher than the numerical results by up to $40 \%$ near choking. These discrepancies are attributed to two factors. First, the model neglects the transient before the quasi-steady expansion is set up, which generates a lower flow velocity than the quasi-steady expansion. Second, our one-dimensional model does not account for two-dimensional effects such as oblique waves generated after valve opening. ${ }^{42}$

Although the two-dimensional numerical simulations show that the flow at the end of the filling process is nonuniform in the downstream half of the tube, ${ }^{42}$ the spatial average of the pressure and velocity in the tube are reasonably well predicted by our model. For values of the pressure ratio between 2 and 10, the model predicts a pressure between 5.8 and $22.7 \%$ higher than the numerical results, and a velocity between -11.3 and $+23.5 \%$.

\section{Flow Fluctuations in Plenum}

The unsteady pressure waves generated by valve closing and opening strongly affect the coupled flow in the plenum and the inlet. Because conventional steady inlets are sensitive to downstream pressure fluctuations, it is critical to be able to model these flow fluctuations in the engine.

To model the unsteady flow in the plenum, we solve the unsteady mass and energy equations. Details and assumptions used in the derivation can be found in Ref. 42. The amplitudes of the fluctuations in density, temperature, and pressure in the plenum are

$$
\begin{gathered}
\frac{\Delta \rho_{P}}{\overline{\rho_{P}}}=\frac{\dot{m}_{0} t_{\text {close }}}{2 V_{P} \overline{\overline{\rho_{P}}}} \\
\frac{\Delta T_{P}}{\overline{T_{P}}}=\frac{\gamma-1}{2} \cdot \frac{\dot{m}_{0} t_{\text {close }}}{V_{P} \overline{\rho_{P}}} \\
\frac{\Delta P_{P}}{\overline{P_{P}}}=\frac{\dot{m}_{0} t_{\text {close }}}{V_{P} \overline{\rho_{P}}}\left(\frac{\gamma}{2}+\frac{\gamma-1}{4} \cdot \frac{\dot{m}_{0} t_{\text {close }}}{V_{P} \overline{\rho_{P}}}\right)
\end{gathered}
$$

These amplitudes are all controlled by the same nondimensional parameter, which represents the ratio of the amount of mass added to the system during the closed part of the cycle to the average mass in the plenum. The response of the inlet shock wave to downstream pressure fluctuations has been previously studied in the context of combustion instabilities in ramjets. Culick and Rogers ${ }^{45}$ showed analytically and $\mathrm{Oh}$ et al. ${ }^{46}$ demonstrated through numerical simulation that the shock response decreased with increasing frequency. Recent experiments ${ }^{47}$ have confirmed this result for supersonic inlets specifically designed for PDEs.

\section{PDE Performance Calculation}

The model assumes that the flow in the detonation tube before detonation initiation is uniform, moves at a velocity $U_{\text {fill }}$, and has a pressure equal to the postshock pressure. The conditions in the tube at the end of the filling process are modeled as uniform using the average conditions derived from the numerical simulations. We now use the control volume analysis of Fig. 2 to calculate the performance of our PDE.

\section{PDE Thrust Equation}

Consider computing the cycle average of the thrust equation (5). The momentum and pressure contributions of the detonation tube during the open part of the cycle (from $t_{\text {close }}$ to $\tau$ ) are calculated using the model estimates for velocity and pressure at the valve plane during the open part of the cycle. The cycle-averaged mass equation (1) yields

$$
\int_{0}^{\tau} \dot{m}_{V} u_{V}(t) \mathrm{d} t=t_{\mathrm{open}} \dot{m}_{V}=\tau \dot{m}_{0}
$$

The contribution of the open part of the cycle is ${ }^{42}$

$$
\begin{gathered}
\int_{t_{\text {close }}}^{\tau}\left\{\dot{m}_{V}(t) u_{V}(t) \mathrm{d} t+A_{V}\left[P_{V}(t)-P_{0}\right]\right\} \mathrm{d} t \\
=\tau \dot{m}_{0} u_{V}+A_{V}\left(P_{V}-P_{0}\right) t_{\text {open }}
\end{gathered}
$$

When Eq. (16) is substituted into Eq. (5), the cycle-average thrust can be expressed as

$$
\bar{F}=(1 / \tau) I_{\mathrm{DT}}+\dot{m}_{0}\left(u_{V}-u_{0}\right)+\left(t_{\mathrm{open}} / \tau\right) A_{V}\left(P_{V}-P_{0}\right)
$$

The first term, the detonation tube impulse, is always positive. The second term, the ram effect, is negative because of the flow losses associated with decelerating the flow through the inlet and reaccelerating it unsteadily during the filling process. The third term, associated with the pressure changes associated with valve operation, is positive because the air injected during the filling process is at a higher pressure than the outside air. The sum of the last two terms is always negative ${ }^{42}$ and represents an effective drag caused by flow losses and unsteadiness through the inlet and the plenum.

\section{Specific Impulse and Effect of Purging Time}

The purging time has a strong influence on the specific performance. To see this, consider the mass balance in the detonation tube when the valve is open. At the end of the purge time, fuel is injected into the detonation tube just downstream of the valve. We assume that the detonation tube volume equals the volume of injected detonable mixture (meaning that the length of the detonation tube is being varied with the operating conditions in this model) and suppose ideal mixing at constant conditions to obtain

$$
V=\left[\frac{(1+f)}{1+t_{\text {purge }} / t_{\text {fill }}}\right] \frac{\tau \dot{m}_{0}}{\rho_{i}}
$$

It is critical here to make the distinction between the air mass flow rate $\dot{m}_{0}$ and the average detonable mixture mass flow rate $\rho_{i} V / \tau$. Using the mass balance in the detonation tube, we calculate the average fuel mass flow rate

$$
\dot{m}_{F}=\frac{\rho_{i} V f}{(1+f) \tau}=\frac{\dot{m}_{0} f}{1+t_{\text {purge }} / t_{\text {fill }}}
$$

The fuel-based specific impulse can now be found to be

$I_{\text {spf }}=\frac{\bar{F}}{\dot{m}_{F} g}=I_{\text {spf }_{\mathrm{DT}}}-\frac{1+t_{\text {purge }} / t_{\text {fill }}}{f g}\left[\left(u_{0}-u_{V}\right)-\frac{A_{V}\left(P_{V}-P_{0}\right)}{\dot{m}_{V}}\right]$

Because the term in brackets in Eq. (20) is positive, the specific impulse decreases linearly with increasing purge time. ${ }^{42}$

\section{Detonation Tube Impulse}

The detonation tube impulse term in the thrust equation (17) must be evaluated for various operating conditions. The impulse due to the detonation process alone has been measured ${ }^{1-5}$ for single-cycle operation, and several models have been proposed. ${ }^{3,11,13}$ However, the flow downstream of the propagating detonation wave in a multicycle engine is not at rest because of the filling process and must be accounted for. Experiments ${ }^{3,19,23}$ have been carried out for multicycle operation, but in many cases, impulse can be predicted by the singlecycle estimates ${ }^{13}$ because of the low filling velocity in these tests.

However, during supersonic flight, the average stagnation pressure in the plenum is much higher than the pressure in the tube at the end of the blowdown process. This large pressure ratio generates high filling velocities, which can significantly alter the flowfield and the detonation/blowdown process, and so we include this effect in our model. In this model, we assume that the detonation wave is immediately initiated after valve closing and catches up with the expansion wave generated by the valve closing. The situation corresponds to a detonation wave propagating in a flow moving in the same direction as the filling velocity and is observed in the multicycle numerical simulations of an airbreathing PDE by Wu et al. ${ }^{30}$ and $\mathrm{Ma}$ et al. ${ }^{31}$ 
Detonation Tube Impulse Model

The moving flow ahead of the detonation is assumed to have a velocity $U_{\text {fill }}$. Following the detonation is the Taylor wave (see Refs. 48 and 49), which brings the products back to rest near the closed end of the tube. In the moving-flow case, the energy release across the wave is identical to the no-flow case, and the Chapman-Jouguet (CJ) pressure, temperature, density, and speed of sound are unchanged. However, the wave is now moving at a velocity $U_{\mathrm{CJ}}+U_{\text {fill }}$ with respect to the tube, which results in a stronger flow expansion than in the no-flow case. A similarity solution can be derived using the method of characteristics and is described by Wintenberger. ${ }^{42}$

The detonation tube impulse is calculated as the integral of the pressure trace at the valve plane

$$
I_{\mathrm{DT}}=\int_{0}^{t_{\mathrm{close}}} A_{V}\left[P_{3}(t)-P_{0}\right] \mathrm{d} t
$$

Using dimensional analysis, we idealize the pressure trace at the valve plane and model the pressure trace integral in a similar fashion as described by Wintenberger et al. ${ }^{13}$ (Fig. 5). The pressure history is modeled by a constant pressure region followed by a decay due to gas expansion out of the tube. The pressure integral can be expressed as

$$
\int_{t_{\text {open }}}^{\tau}\left[P_{3}(t)-P_{0}\right] \mathrm{d} t=\Delta P_{3}\left[\frac{L}{U_{\mathrm{CJ}}+U_{\text {fill }}}+(\alpha+\beta) \frac{L}{c_{3}}\right]
$$

where $\Delta P_{3}=P_{3}-P_{0}, \alpha$ is a nondimensional parameter characterizing the time taken by the first reflected characteristic at the open end to reach the closed end, and $\beta$ is a non-dimensional parameter characterizing the pressure decay period ${ }^{13}$. The first term in the second set of square brackets in Eq. (22) is equal to the time taken by the detonation wave to propagate to the open end. As in the no-flow case, it is possible to derive a similarity solution for the reflection of the first characteristic at the open end and to calculate $\alpha$ analytically. The reader is referred to Wintenberger et al. ${ }^{13}$ for the details of the derivation in the no-flow case. For the moving-flow case, the value of $\alpha$ is

$$
\begin{aligned}
\alpha= & \frac{c_{3}}{U_{\mathrm{CJ}}+U_{\mathrm{fill}}} \\
& \times\left\{2\left[\frac{\gamma_{b}-1}{\gamma_{b}+1}\left(\frac{c_{3}-u_{\mathrm{CJ}}}{c_{\mathrm{CJ}}}+\frac{2}{\gamma_{b}-1}\right)\right]^{-\left(\gamma_{b}+1\right) / 2\left(\gamma_{b}-1\right)}-1\right\}
\end{aligned}
$$

The value of $\beta$ is assumed to be independent of the filling velocity, and the same value as that by Wintenberger et al. ${ }^{13}$ is used: $\beta=0.53$. It is expected and observed ${ }^{50}$ that $\beta$ will also be a function of the pressure ratio $P_{3} / P_{0}$ and, in addition, of the freestream Mach number, an effect that no observations are available for at the present time. When improved correlations for $\beta$ are developed, the model can be revised to include these effects.

\section{Comparison with Numerical Simulations of Detonation Process}

To validate the model for the valve plane pressure integration [Eq. (22)], the flow was simulated numerically with AMRITA. ${ }^{43}$ The axisymmetric computational domain consists of a tube of length $L$ closed at the left end and open to a half-space at the right end. The moving flow was assumed to be uniform inside the tube, and outside was a rectangular profile representing an idealized pressurematched jet flow at constant velocity $U_{\text {fill }}$. A modified Taylor wave similarity solution (see Ref. 42) was used as an initial condition, assuming that the detonation has just reached the open end of the tube when the simulation is started. This solution was calculated using a one- $\gamma$ model for detonations ${ }^{51,52}$ for a nondimensional energy release $q / R T_{i}=40$ across the detonation and $\gamma=1.2$ for reactants and products. The corresponding $\mathrm{CJ}$ parameters are $M_{\mathrm{CJ}}=5.6$ and $P_{\mathrm{CJ}} / P_{i}=17.5$, values representative of stoichiometric hydrocarbon-air mixtures. The pressure $P_{i}$ ahead of the detonation wave was taken equal to the pressure $P_{0}$ outside the detonation tube.

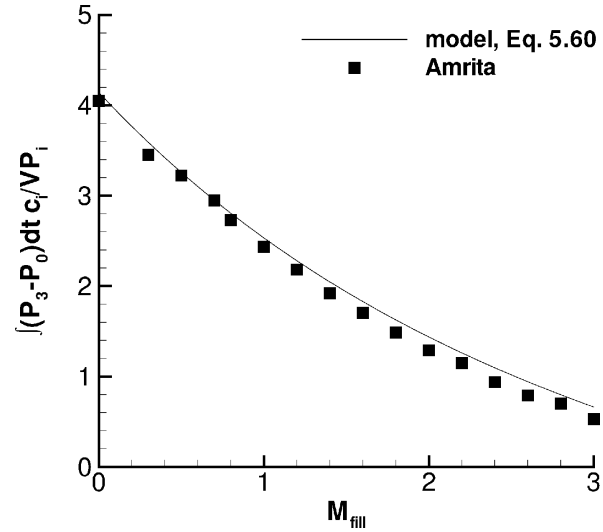

Fig. 8 Nondimensional detonation tube impulse as function of filling Mach number; comparison of model predictions based on Eq. (22) and results of numerical simulations with $\mathrm{AMRITA}^{43}: q / R T_{i}=40$ and $\gamma=1.2$.

The configuration we adopted for the moving flow is a very idealized representation of the flow at the end of the filling process. This flow will, in reality, include vortices associated with the unsteady flow and the unstable jet shear layers. However, the analysis of the numerical simulations showed that the flow in the tube is one-dimensional except for within one to two tube diameters from the open end, as observed in the no-flow case by Wintenberger et al. ${ }^{13}$ Because the exit flow is choked for most of the process, we expect that the influence of our simplified jet profile on the valve plane pressure integration is minimal.

Figure 8 shows the comparison of the nondimensionalized valve plane pressure integral with the predictions of our model based on Eq. (22) as a function of the filling Mach number. The numerical pressure integration was carried out for a time equal to $20 t_{\mathrm{CJ}}$, where $t_{\mathrm{CJ}}=L / U_{\mathrm{CJ}}$. As the filling Mach number increases, the flow expansion through the Taylor wave is more severe, and the plateau pressure behind the Taylor wave $P_{3}$ decreases. Even though $P_{3}$ is lower, the blowdown process is accelerated due to the presence of the initial moving flow. The overall result is that the detonation tube impulse decreases with increasing filling Mach number, as shown in Fig. 8. The model agrees reasonably well with the results of the numerical simulations. It generally overpredicts the results of the numerical simulations by as much as $25 \%$ at higher filling Mach numbers. The agreement is better at lower Mach numbers (within $11 \%$ error for $M_{\text {fill }} \leq 2$ and $4 \%$ for $M_{\text {fill }} \leq 1$ ).

\section{Application to Hydrogen- and JP10-Fueled PDEs}

We have carried out performance calculations with hydrogen and JP10 fuels and compared the results with ideal ramjet performance. The performance calculations are presented for supersonic flight only because the assumptions made in the derivation of the model become invalid for subsonic flight. The results presented here do not represent the ideal performance from an optimized PDE. In particular, the addition of an exit nozzle on the engine is expected to substantially improve performance.

\section{Input Parameters}

The input parameters for the performance model consist of the freestream conditions and flight Mach number, the fuel type and stoichiometry, the valve close time, and the purge time. In the following performance calculations, the fuel-air mixture is assumed to be stoichiometric.

The stagnation pressure loss across the inlet during supersonic flight is modeled using the military specification MIL-E-5008B (Ref. 53), which specifies the stagnation pressure ratio across the inlet as a function of the flight Mach number for $M_{0}>1$,

$$
P_{t 2} / P_{t 0}=1-0.075\left(M_{0}-1\right)^{1.35}
$$

In our calculations, we assumed a fixed valve area $A_{V}$ and valve close time $t_{\text {close }}$. Other parameters such as valve open time and 

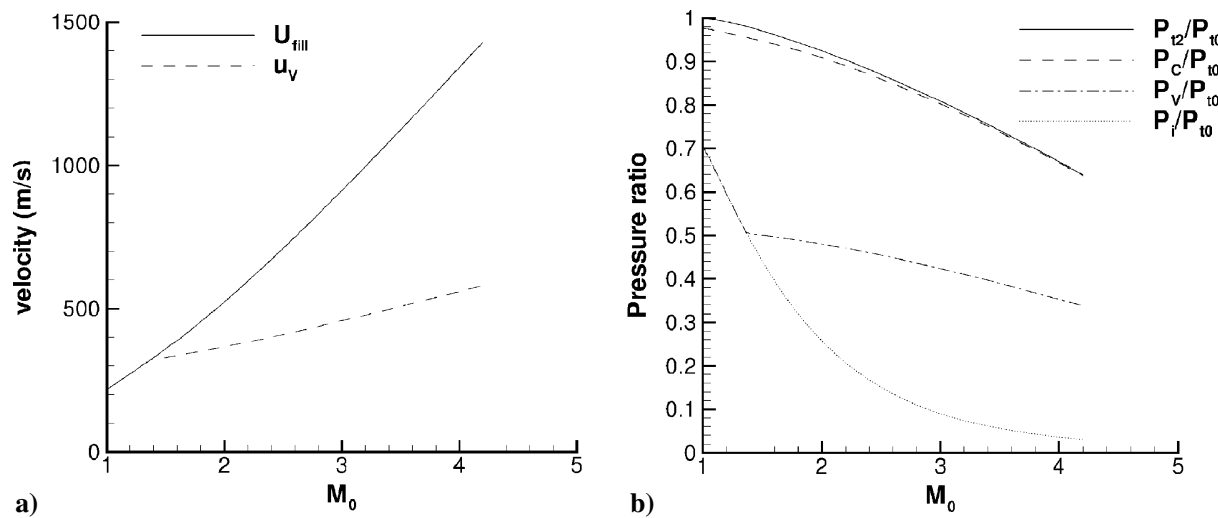

Fig. 9 PDE operating with stoichiometric hydrogen-air at altitude of $10 \mathrm{~km}$ : a) velocity and b) pressure at selected points.

detonation tube length are determined by the periodicity of the system. The calculation of the properties at the valve plane and the initial conditions in the detonation tube require the knowledge of the specific heat ratio and the speed of sound in the burned gases at the end of the blowdown process. These parameters and the $\mathbf{C J}$ detonation properties are obtained by carrying out detonation equilibrium computations using realistic thermochemistry. ${ }^{54}$ The speed of sound in the burned gases is calculated assuming that the flow is isentropically expanded from the $\mathrm{CJ}$ pressure to atmospheric pressure. The iterative method used to obtain the solution is described in detail by Wintenberger. ${ }^{42}$

\section{Hydrogen-Fueled PDE}

\section{Conditions Inside Engine}

The calculation of performance parameters first requires solving for the conditions inside the engine. Figure 9 shows the velocity and pressure at selected points for a PDE operating with stoichiometric hydrogen-air at an altitude of $10 \mathrm{~km}$, with parameters $A_{0}=0.004 \mathrm{~m}^{2}, A_{2}=0.04 \mathrm{~m}^{2}$, and $A_{V}=0.006 \mathrm{~m}^{2}$. Figure 9a shows filling velocity and velocity at the valve plane as a function of flight Mach number. Figure $9 \mathrm{~b}$ shows inlet stagnation pressure, plenum pressure, pressure at the valve plane, and filling pressure nondimensionalized with freestream total pressure as a function of flight Mach number.

In this case, the flow at the valve plane during the filling process is predicted to remain subsonic up to a flight Mach number of 1.36. Thus, the two velocity curves on Fig. 9 match for $M_{0}<1.36$ but diverge at higher values of $M_{0}$ because $U_{\text {fill }}>u_{V}$. The filling velocity increases with increasing flight Mach number because of the increasing stagnation pressure in the plenum, which generates a stronger shock wave at valve opening.

The model filling velocity was compared with the results of the numerical simulations of $\mathrm{Wu}$ et al.$^{30}$ for an airbreathing PDE with a straight detonation tube for a PDE flying at $9.3 \mathrm{~km}$ altitude and at Mach 2.1. The flow observed in these simulations is qualitatively similar to the flow predicted by the model in the detonation tube and represented schematically in Fig. 6. The numerical simulations yielded a filling velocity of about $500 \mathrm{~m} / \mathrm{s}$, whereas the prediction of our model for this case is $539 \mathrm{~m} / \mathrm{s}$.

The ratio of inlet stagnation pressure to freestream stagnation pressure in Fig. 9 decreases with increasing flight Mach number because of the increasing stagnation pressure losses through the inlet [Eq. (24)]. Additional losses occur in the plenum due to flow unsteadiness. The pressure at the valve plane equals the filling pressure until the flow at the valve plane becomes sonic. At higher flight Mach numbers, the filling pressure is lower because of the additional unsteady expansion in the tube. The ratio of the filling pressure to the freestream stagnation pressure decreases sharply with increasing flight Mach number because of the increasing filling velocity (Fig. 9).

\section{Performance Variation with Flight Mach Number}

The specific impulse for a hydrogen-air PDE is shown in Fig. 10 as a function of the flight Mach number for conditions at sea

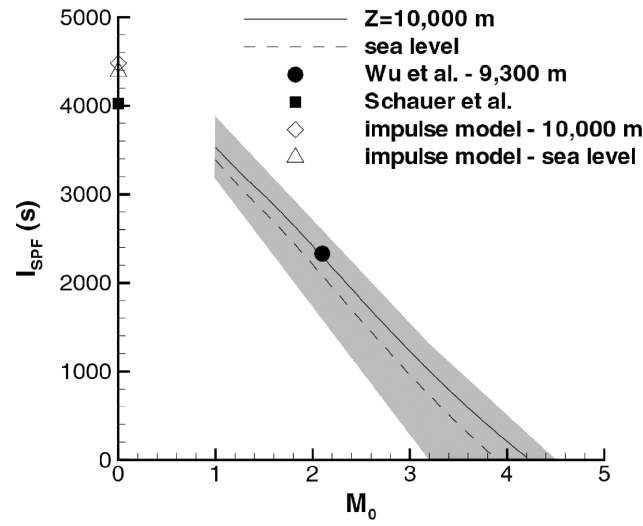

Fig. 10 Specific impulse of single-tube PDE operating with stoichiometric hydrogen-air as function of flight Mach number at sea level and at altitude of $10 \mathrm{~km}$.

level and at 10-km altitude; other parameters are $A_{0}=0.004 \mathrm{~m}^{2}$, $A_{2}=0.04 \mathrm{~m}^{2}$, and $A_{V}=0.006 \mathrm{~m}^{2}$. These results are for no purging and represent the maximum possible values for this configuration. Even though the model assumptions do not apply for subsonic flight, linear extrapolation of the results to $M_{0}=0$ are close to the observed and computed static values. Our single-tube PDE generates thrust up to a flight Mach number of 3.9 at sea level and 4.2 at an altitude of $10 \mathrm{~km}$. Data from multicycle numerical simulations by $\mathrm{Wu}$ et al. ${ }^{30}$ for $M_{0}=2.1$ at $9300-\mathrm{m}$ altitude are shown. Experimental data from Schauer et al. ${ }^{23}$ and impulse model predictions ${ }^{13}$ are also given as a reference for the static $\left(M_{0}=0\right)$ case. The shaded area represents the possible range of values due to the uncertainty in the input parameters and model assumptions.

The specific impulse decreases almost linearly with increasing flight Mach number from a value at $M_{0}=1$ of about $3530 \mathrm{~s}$ at $10 \mathrm{~km}$ and $3390 \mathrm{~s}$ at sea level. This behavior is mainly due to the reduction in detonation tube impulse with increasing flight Mach number, which is caused by the increase in filling velocity (Figs. 9 and 8). The variation with Mach number of the sum of the momentum and pressure terms in Eq. (20) is much smaller than that of the detonation tube impulse term. ${ }^{42}$ Figure 10 also shows a datum from the numerical simulations by $\mathrm{Wu}$ et al. ${ }^{30}$ The baseline case value for the specific impulse for a straight detonation tube is $2328 \mathrm{~s}$ (Ref. 30). Our model prediction for the same configuration and flight conditions is $2286 \mathrm{~s}$.

\section{Performance Variation with Altitude}

The specific impulse at sea level is systematically lower than the specific impulse at $10 \mathrm{~km}$ by $150-300 \mathrm{~s}$, as shown in Fig. 10. The freestream pressure and temperature both change with altitude. However, the specific impulse is independent of the freestream pressure because the detonation tube specific impulse is essentially independent of the initial state in the static case. ${ }^{13}$ This conclusion can be extended to the moving-flow case because the filling velocity is 
independent of the freestream static pressure. Because the momentum and pressure terms in the specific impulse expression are also unaffected by pressure variations, the engine specific impulse does not depend on the freestream pressure.

Specific impulse decreases with increasing freestream static temperature. Although the magnitude of the drag terms in Eq. (20) increases with the freestream temperature, it is the change in detonation tube impulse that is primarily responsible for the reduction in specific impulse. Increasing the freestream temperature results in a stronger shock wave at valve opening and, therefore, a higher filling velocity. The variation observed is attributed to the effect of the filling velocity because the detonation tube specific impulse is essentially independent of initial conditions. ${ }^{13}$ Indeed, increasing $T_{0}$ from 223 to $288 \mathrm{~K}$ causes an increase in $U_{\text {fill }}$ of about $10 \%$, which translates to a detonation tube impulse decrease of 100-180 s.

\section{JP10-Fueled PDE}

The specific impulse of a JP10-fueled PDE is shown in Fig. 11 for an altitude of $10 \mathrm{~km}$; the other parameters are $A_{0}=0.004 \mathrm{~m}^{2}$, $A_{2}=0.04 \mathrm{~m}^{2}$, and $A_{V}=0.006 \mathrm{~m}^{2}$. Data from multicycle numerical simulations by $\mathrm{Wu}$ et al. ${ }^{30}$ for $M_{0}=2.1$ at $9300-\mathrm{m}$ altitude are shown. Experimental data from Schauer et al. ${ }^{23}$ and Wintenberger et al. ${ }^{55}$ and impulse model predictions ${ }^{13}$ are also given as a reference for the static $\left(M_{0}=0\right)$ case. The specific impulse decreases almost linearly with increasing $M_{0}$ from a value of $1370 \mathrm{~s}$ at $M_{0}=1$ and vanishes at $M_{0} \approx 4$. There are additional issues associated with the use of a liquid fuel such as JP10 that merit discussion.

Preignition of the JP10-air mixture is expected ${ }^{42}$ above Mach 3 if the fuel injection system is located at the valve plane. Preignition can result in a significant decrease in detonation tube impulse due to potential expulsion of unburned reactants out of the detonation tube ${ }^{5}$ and a reduced thrust surface effectiveness. ${ }^{56}$ The design of the fuel injection system for high Mach numbers has to take into account this issue. An option is to move it downstream of the valve plane, where the temperature is lower due to the unsteady expansion downstream of the valve.

Another issue with the use of liquid hydrocarbon fuels is related to potential condensation of the fuel in the detonation tube due to the low filling temperature. For the case considered here, the filling temperature remains under $300 \mathrm{~K}$ as long as $M_{0}<2.3$. To vaporize the fuel completely for a stoichiometric JP10-air mixture at $100 \mathrm{kPa}$, the temperature has to be at least $330 \mathrm{~K}$ (Ref. 57). Both pressure and temperature in the detonation tube vary with flight Mach number, and whether all of the liquid fuel injected will vaporize depends on its vapor pressure under these conditions. It is substantially more difficult to establish self-sustaining detonations in liquid fuel sprays than gases due to higher initiation energies ${ }^{58}$ and larger reaction zones. It is possible that not all of the fuel corresponding to stoichiometric quantity will be able to vaporize, and the engine may have to be run at a leaner composition depending on the flight conditions.

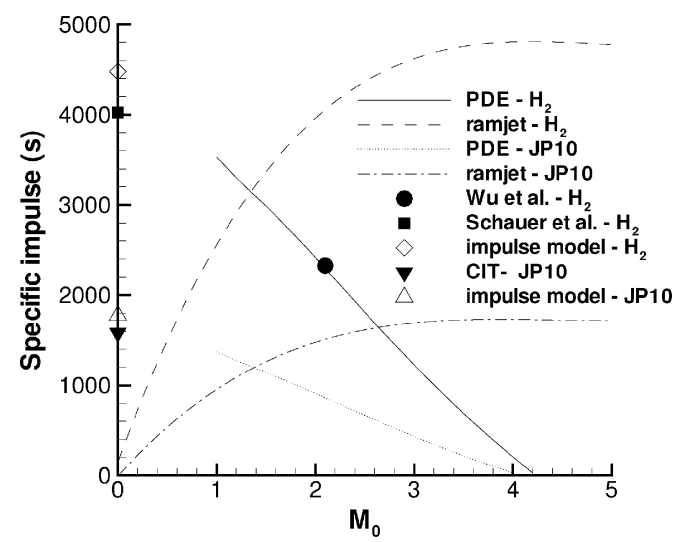

Fig. 11 Specific impulse of single-tube airbreathing PDE compared to ideal ramjet operating with stoichiometric hydrogen-air and JP10-air at altitude of $10 \mathrm{~km}$.
Table 1 Uncertainty of some model parameters derived from results of numerical simulations of filling and detonation processes

\begin{tabular}{lcc}
\hline \hline Parameter & Minimum, $\%$ & Maximum, $\%$ \\
\hline$U_{\text {fill }}$ & -11.3 & +23.5 \\
$u_{V}$ & 0 & +40 \\
$P_{V}$ & -20.5 & +13.4 \\
$P_{i}$ & +5.8 & +22.7 \\
$I_{\text {spf }}$ & 0 & +25 \\
\hline \hline
\end{tabular}

\section{Limitations of Present Model and Uncertainty Analysis}

Our model is based on one-dimensional flow. It also assumes a uniform flow in the detonation tube before detonation initiation. Furthermore, the state in the detonation tube before valve opening is assumed to be a uniform, stationary flow of hot products expanded to the freestream pressure. The present model cannot account for two-dimensional effects resulting from engine internal geometry, flow nonuniformities, and variations in valve open and close times that affect the downstream boundary conditions. For this reason, it is important to validate our approach against available computational and experimental results.

Unfortunately, at this time, there is no standard set of results to which our model can be compared over the entire range of flight conditions. At present, only Wu et al. ${ }^{30}$ and Ma et al. ${ }^{31}$ have published results for the configuration we are considering. Our work agrees within $2 \%$ with their results at a single flight condition and, by construction, agrees with existing models and experiments at static conditions. Absent other validation points, we have tried to develop more confidence in the results by estimating the effect of the uncertainty in modeling parameters on the performance computations.

We know from our numerical simulations of the filling process the uncertainty of the model predictions for some of the parameters, shown in Table 1. We estimated the model uncertainty for a case corresponding to a stoichiometric hydrogen-air PDE flying at $10 \mathrm{~km}$ with no purging. We evaluated how the specific impulse varies with each parameter with calculations corresponding to extreme assumptions. ${ }^{42}$ The region of uncertainty is shown in Fig. 10 as the gray shaded area around the predicted specific impulse curve at $10 \mathrm{~km}$. As expected, the uncertainty margin increases with increasing flight Mach number due to the growing uncertainty on the detonation tube impulse. The uncertainty for the specific impulse at $M_{0}=1$ is $\pm 9.9 \%$ and, at $M_{0}=2,-36.5 \% /+12.7 \%$.

\section{Comparison with Ideal Ramjet}

The specific impulse of the model PDE is compared in Fig. 11 with that of the ideal ramjet at flight conditions corresponding to $10-\mathrm{km}$ altitude for stoichiometric hydrogen-and JP10-air. The ideal ramjet performance was calculated following the ideal Brayton cycle, taking into account the stagnation pressure loss across the inlet [Eq. (24)]. Combustion at constant pressure was computed using realistic thermochemistry, ${ }^{54}$ and performance was calculated assuming thermodynamic equilibrium at every point in the nozzle. According to our performance predictions, the single-tube airbreathing PDE in the present configuration (straight detonation tube) has a higher specific impulse than the ideal ramjet for $M_{0}<1.35$ for both hydrogen and JP10 fuels.

The lack of performance of the PDE at higher flight Mach numbers is attributed to the decreasing detonation tube impulse. The present configuration results in very high filling velocities (higher than $500 \mathrm{~m} / \mathrm{s}$ for $M_{0}>2$ ), which has two main consequences. First, the pressure and density of the reactants before detonation initiation are low compared to the corresponding properties in the plenum (Fig. 9). With the detonation tube impulse being proportional to the initial mixture density, ${ }^{13}$ a low reactant density is detrimental to the specific impulse. The straight-tube PDE exhibits the same problem as the standard pulsejet, ${ }^{34}$ which is the inability of the engine to sustain ram pressure in the detonation tube during the filling process. Indeed, our specific impulse predictions for the straight-tube 
PDE display the same behavior as Foa's predictions ${ }^{34}$ for the standard pulsejet, decreasing almost linearly with increasing flight Mach number. Second, as shown in Fig. 8, the detonation tube impulse decreases sharply with increasing filling velocity. For example, if the filling velocity were to be reduced to one-half of its value at $M_{0}=2$ for a hydrogen-air PDE flying at $10 \mathrm{~km}$, our model predicts that the detonation tube impulse would increase by as much as $36 \%$.

The results of our performance calculations show that the unoptimized, straight-tube PDE is not competitive with the ramjet at high supersonic flight Mach numbers. However, this comparison of our unoptimized, straight-tube PDE with an optimized-nozzle ramjet immediately brings up the issue of the need to consider further optimization of the PDE. In particular, the addition of diverging and converging-diverging nozzles has been shown to improve significantly the static impulse of detonation tubes, especially at high pressure ratios. ${ }^{50,59,60}$ Adding a choked converging-diverging exit nozzle to an airbreathing PDE has been proposed by several researchers ${ }^{30,61}$ as a means to increase the chamber pressure and decrease the effective filling velocity. The strong sensitivity of the detonation tube impulse to the filling velocity suggests a potential for improving performance, provided that the filling velocity can be decreased without excessive internal flow losses. The numerical simulations of Wu et al. ${ }^{30}$ and Ma et al. ${ }^{31}$ support this idea, showing an increase in specific impulse of up to $45 \%$ with the addition of a converging-diverging nozzle. The idea of extending the present model to include a nozzle is interesting, but the many additional wave interactions generated by the area changes in the nozzle make it difficult to develop a model consistent with our approach. The present calculations can be used as a baseline case for nozzle optimization studies.

\section{Conclusions}

We have developed a simple model for predicting the performance of a single-tube, supersonic, airbreathing PDE based on gasdynamics and control volume methods. The model takes into account the behavior of the flow in the various components of the engine and their respective coupling. We have used our model and simulation of individual components to draw the following conclusions:

1) The filling process is characterized by a shock wave generated at valve opening and propagating in the detonation tube and a combination of unsteady and steady expansions between the plenum and the detonation tube.

2) The unsteadiness of the flow in the plenum, which is coupled to the flow in the detonation tube, causes average stagnation pressure losses.

3) The flow in the plenum is characterized by density, temperature, and pressure oscillations due to the opening and closing of the valve during a cycle.

4) The thrust of the engine was calculated using an unsteady opensystem control volume analysis. It was found to be the sum of three terms representing the detonation tube impulse, the momentum, and the pressure at the valve plane.

5) The detonation tube impulse was calculated by modifying our single-cycle impulse mode $1^{13}$ to take into account the effect of detonation propagation into a moving flow generated by the filling process. The detonation tube impulse is found to decrease sharply with increasing filling velocity.

6) Performance calculations for hydrogen- and JP10-fueled PDEs showed that the specific impulse decreases approximately linearly with increasing flight Mach number and that single-tube PDEs generate thrust up to a flight Mach number of about 4 .

7) PDEs with a straight detonation tube have a higher specific impulse than the ramjet below a minimum value of the flight Mach number, equal to 1.35 in the present case. PDE performance was found to be very sensitive to the value of the filling velocity, and substantial potential improvements may be possible with a convergingdiverging nozzle at the exit.

Although items 1-3 have long been recognized by PDE researchers, we have provided quantification of these effects and show how they depend on the system parameters. Item 4 and the subsequent conclusions in items 6 and 7 provide quantitative predictions of how the performance of a straight-tube PDE will depend on flight Mach number. The previous studies have computed performance at single flight Mach number only. Item 5 has not been recognized explicitly by the previous computation studies, and we have shown how to take this in account explicitly in the spirit of the gasdynamic model ${ }^{13}$ that has been successful in predicting low-speed PDE performance. We recognize that significant performance improvements may be obtained with the addition of an optimized nozzle and the present results do not represent the best performance that can be obtained for PDEs.

\section{Acknowledgments}

This work was supported by Stanford University Contract PY-1905 under the U.S. Department of the Navy Grant N0001402-1-0589, "Pulse Detonation Engines: Initiation, Propagation, and Performance."

\section{References}

${ }^{1}$ Nicholls, J. A., Wilkinson, H. R., and Morrison, R. B., "Intermittent Detonation as a Thrust-Producing Mechanism," Jet Propulsion, Vol. 27, No. 5, 1957, pp. 534-541.

${ }^{2}$ Zhdan, S. A., Mitrofanov, V. V., and Sychev, A. I., "Reactive Impulse from the Explosion of a Gas Mixture in a Semi-Infinite Space," Combustion, Explosion and Shock Waves, Vol. 30, No. 5, 1994, pp. 657-663.

${ }^{3}$ Zitoun, R., and Desbordes, D., "Propulsive Performances of Pulsed Detonations," Combustion Science and Technology, Vol. 144, No. 1-6, 1999, pp. 93-114.

${ }^{4}$ Harris, P. G., Farinaccio, R., Stowe, R. A., Higgins, A. J., Thibault, P. A., and Laviolette, J. P., "The Effect of DDT-Distance on Impulse in a Detonation Tube," AIAA Paper 2001-3467, July 2001.

${ }^{5}$ Cooper, M., Jackson, S., Austin, J., Wintenberger, E., and Shepherd, J. E., "Direct Experimental Impulse Measurements for Deflagrations and Detonations," Journal of Propulsion and Power, Vol. 18, No. 5, 2002, pp. 1033-1041.

${ }^{6}$ Kiyanda, C. B., Tanguay, V., Higgins, A. J., and Lee, J. H. S., "Effect of Transient Gasdynamic Processes on the Impulse of PulseDetonation Engines," Journal of Propulsion and Power, Vol. 18, No. 5, 2002 , pp. 1124-1126.

${ }^{7}$ Mattison, D., Oehischlaeger, M. A., Morris, C. I., Owens, Z. C., Barbour, E. A., Jeffries, J. B., and Hanson, R. K., "Evaluation of Pulse Detonation Engine Modeling Using Laser-Based Temperature and $\mathrm{OH}$ Concentration Measurements," Proceedings of the Combustion Institute, Vol. 30, No. 2, 2005, pp. 2799-2807.

${ }^{8}$ Kailasanath, K., and Patnaik, G., "Performance Estimates of Pulsed Detonation Engines," Proceedings of the 28th International Symposium on Combustion, Combustion Inst., Pittsburgh, PA, 2000, pp. 595-601.

${ }^{9}$ Kailasanath, K., Patnaik, G., and Li, C., "The Flowfield and Performance of Pulse Detonation Engines," Proceedings of the 29th International Symposium on Combustion, Combustion Inst., Pittsburgh, PA, 2002, pp. 2855-2862.

${ }^{10}$ Morris, C., "Numerical Modeling of Single-Pulse Gasdynamics and Performance of Pulse-Detonation Rocket Engines," Journal of Propulsion and Power, Vol. 21, No. 3, 2005, pp. 527-538.

${ }^{11}$ Endo, T., and Fujiwara, T., "A Simplified Analysis on a Pulse Detonation Engine," Transactions of the Japanese Society for Aeronautical and Space Sciences, Vol. 44, No. 146, 2002, pp. 217-222.

${ }^{12}$ Ebrahimi, H. B., Mohanraj, R., and Merkle, C. L., "Multilevel Analysis of Pulsed-Detonation Engines," Journal of Propulsion and Power, Vol. 18, No. 2, 2002, pp. 225-232.

${ }^{13}$ Wintenberger, E., Austin, J. M., Cooper, M., Jackson, S., and Shepherd, J. E., "Analytical Model for the Impulse of Single-Cycle Pulse-Detonation Tube," Journal of Propulsion and Power, Vol. 19, No. 1, 2003, pp. 22-38.

${ }^{14}$ Endo, T., Kasahara, J., Matsuo, A., Inaba, K., Sato, S., and Fujiwara, T., "Pressure History at the Thrust Wall of a Simplified Pulse Detonation Engine," AIAA Journal, Vol. 42, No. 9, 2004, pp. 1921-1930.

${ }^{15}$ Radulescu, M. I., and Hanson, R. K., "Effect of Heat Loss on PulseDetonation-Engine Flowfields and Performance," Journal of Propulsion and Power, Vol. 21, No. 2, 2005, pp. 274-285.

${ }^{16}$ Kailasanath, K., Patnaik, G., and Li, C., "Computational Studies of Pulse Detonation Engine: A Status Report," AIAA Paper 99-2634, June 1999.

${ }^{17}$ Kailasanath, K., "Recent Developments in the Research on Pulse Detonation Engines," AIAA Journal, Vol. 41, No. 2, 2003, pp. 145-159.

${ }^{18}$ Owens, Z. C., Mattison, D., Barbour, E. A., Morris, C. I., and Hanson, R. K., "Flowfield Characterization and Simulation Validation of MultipleGeometry PDEs Using Cesium-Based Velocimetry," Proceedings of the Combustion Institute, Vol. 30, No. 2, 2005, pp. 2791-2798. 
${ }^{19}$ Kasahara, J., Takazawa, K., Arai, T., and Matsuo, A., "Experimental Study of Impulse and Heat Transfer on Pulse Detonation Engines," AIAA Paper 2002-4071, July 2002.

${ }^{20}$ Brophy, C. M., Werner, L. S., and Sinibaldi, J. O., "Performance Characterization of a Valveless Pulse Detonation Engine," AIAA Paper 2003-1344, Jan. 2003

${ }^{21}$ Hoke, J. L., Bradley, R. P., and Schauer, F. R., "Impact of DDT Mechanism, Combustion Wave Speed, Temperature, and Charge Quality on PulsedDetonation-Engine Performance,” AIAA Paper 2005-1342, Jan. 2005.

${ }^{22}$ Tangirala, V., Dean, A. J., Pinard, P. F., and Varatharajan, B., "Investigations of Cycle Processes in a Pulsed Detonation Engine Operating on Fuel-Air Mixtures," Proceedings of the Combustion Institute, Vol. 30, No. 2 , 2005, pp. 2817-2824.

${ }^{23}$ Schauer, F., Stutrud, J., and Bradley, R., "Detonation Initiation Studies and Performance Results for Pulsed Detonation Engines," AIAA Paper 20011129, Jan. 2001

${ }^{24}$ Schauer, F. R., Miser, C. L., Tucker, K. C., Bradley, R. P., and Hoke, J. L., "Detonation Initiation of Hydrocarbon-Air Mixtures in a Pulsed Detonation Engine," AIAA Paper 2005-1343, Jan. 2005.

${ }^{25}$ Schauer, F., Stutrud, J., Bradley, R., Katta, V., and Hoke, J., "Detonation Initiation and Performance in Complex Hydrocarbon Fueled Pulsed Detonation Engines,' JANNAF Paper I-05, July 2001.

${ }^{26}$ Cambier, J. L., and Tegner, J. K., "Strategies for Pulsed-Detonation Engine Performance Optimization," Journal of Propulsion and Power, Vol. 14, No. 4, 1998, pp. 489-498.

${ }^{27}$ Paxson, D. E., "Performance Evaluation Method for Ideal Airbreathing Pulse-Detonation Engines," Journal of Propulsion and Power, Vol. 20, No. 5 , 2004, pp. 945-950.

${ }^{28}$ Bratkovich, T., and Bussing, T., "A Pulse Detonation Engine Performance Model," AIAA Paper 95-3155, July 1995.

${ }^{29}$ Kaemming, T., "Integrated Vehicle Comparison of Turbo-Ramjet Engine and Pulsed Detonation Engine (PDE)," Journal of Engineering for Gas Turbines and Power, Vol. 125, No. 1, 2003, pp. 257-262.

${ }^{30} \mathrm{Wu}$, Y., Ma, F., and Yang, V., "System Performance and Thermodynamic Cycle Analysis of Airbreathing Pulse-Detonation Engines," Journal of Propulsion and Power, Vol. 19, No. 4, 2003, pp. 556-567.

${ }^{31}$ Ma, F.-H., Choi, J.-Y., and Yang, V., "Thrust Chamber Dynamics and Propulsive Performance of Single-Tube Pulse-Detonation Engines," Journal of Propulsion and Power, Vol. 21, No. 3, 2005, pp. 512-526.

${ }^{32}$ Ma, F.-H., Choi, J.-Y., and Yang, V., "Thrust Chamber Dynamics and Propulsive Performance of Multitube Pulse-Detonation Engines," Journal of Propulsion and Power, Vol. 21, No. 4, 2005, pp. 681-691

${ }^{33}$ Heiser, W. H., and Pratt, D. T., "Thermodynamic Cycle Analysis of Pulse-Detonation Engines," Journal of Propulsion and Power, Vol. 18, No. 1, 2002, pp. 68-76.

${ }^{34}$ Foa, J. V., Elements of Flight Propulsion, Wiley, New York, 1960.

${ }^{35}$ Bussing, T., and Pappas, G., "Pulse Detonation Engine Theory and Concepts," Progress in Astronautics and Aeronautics, Vol. 165, 1996, pp. 421-472.

${ }^{36}$ Kentfield, J. A. C., "Fundamentals of Idealized Airbreathing PulseDetonation Engines," Journal of Propulsion and Power, Vol. 18, No. 1, 2002, pp. 77-83.

${ }^{37}$ Talley, D., and Coy, E., "Constant Volume Limit of Pulsed Propulsion for a Constant Gamma Ideal Gas," Journal of Propulsion and Power, Vol. 18, No. 2, 2002, pp. 400-406.

${ }^{38}$ Harris, P. G., Guzik, S., Farinaccio, R., Stowe, R. A., Whitehouse, D., Josey, T., Hawkin, D., Ripley, R., Link, R., Higgins, A. J., and Thibault, P. A., "Comparative Evaluation of Performance Models of Pulse Detonation Engines," AIAA Paper 2002-3912, July 2002.

${ }^{39}$ Harris, P. G., Ripley, R. C., and Guzik, S. M., "Single-Tube TwoDimensional Evaluation of Pulse Detonation Engine as a Ramjet Replacement," AIAA Paper 2004-3744, July 2004.
${ }^{40}$ Harris, P. G., Guzik, S. M., and Stowe, R. A., "Design Methodology for a Pulse Detonation Engine as a Ramjet Replacement," AIAA Paper 20043400, July 2004

${ }^{41}$ Lynch, E. D., and Edelman, R. B., "Analysis of the Pulse Detonation Wave Engine," Progress in Astronautics and Aeronautics, Vol. 165, 1996, pp. 473-516.

${ }^{42}$ Wintenberger, E., "Application of Steady and Unsteady Detonation Waves to Propulsion,” Ph.D. Dissertation, Graduate Aeronautical Laboratories at the California Institute of Technology, California Inst. of Technology, Pasadena, CA, June 2004

${ }^{43}$ Quirk, J. J., AMRITA-A Computational Facility (for CFD Modelling), VKI 29th CFD Lecture Series, von Kármán Inst. for Fluid Dynamics, RhodeSaint-Genése, Belgium, 1998

${ }^{44}$ Glass, I. I., and Sislian, J. P., Nonstationary Flows and Shock Waves, Clarendon, Oxford, England, U.K., 1994.

${ }^{45}$ Culick, F. E. C., and Rogers, T., "Response of Normal Shocks in Diffusers," AIAA Journal, Vol. 21, No. 10, 1983, pp. 1382-1390.

${ }^{46}$ Oh, J. Y., Ma, F., Hsieh, S.-Y., and Yang, V., "Interactions Between Shock and Acoustic Waves in a Supersonic Inlet Diffuser," Journal of Propulsion and Power, Vol. 21, No. 3, 2005, pp. 486-495.

${ }^{47}$ Mullagiri, S., Segal, C., and Hubner, P. J., "Oscillating Flows in a Model Pulse Detonation Engine," AIAA Journal, Vol. 41, No. 2, 2003, pp. 324-326.

${ }^{48}$ Zel'dovich, Y. B., "On the Theory of the Propagation of Detonations in Gaseous Systems," Journal of Experimental and Theoretical Physics, Vol. 10, No. 5, 1940, pp. 542-568; also NACA TM 1261, 1950.

${ }^{49}$ Taylor, G. I., "The Dynamics of the Combustion Products Behind Plane and Spherical Detonation Fronts in Explosives," Proceedings of the Royal Society of London, Series A: Mathematical and Physical Sciences, Vol. A200, (1061), 1950, pp. 235-247.

${ }^{50}$ Cooper, M., and Shepherd, J. E., "Effect of Transient Nozzle Flow on Detonation Tube Impulse," AIAA Paper 2004-3914, July 2004.

${ }^{51}$ Fickett, W., and Davis, W. C., Detonation Theory and Experiment, Dover, Mineola, NY, 2001.

${ }^{52}$ Thompson, P. A., Compressible Fluid Dynamics, Advanced Engineering Series, Rensselaer Polytechnic Inst., Troy, NY, 1988, pp. 347-359.

${ }^{53}$ Mattingly, J. D., Heiser, W. H., and Daley, D. H., Aircraft Engine Design, AIAA Educational Series, AIAA, New York, 1987.

${ }^{54}$ Reynolds, W., "The Element Potential Method for Chemical Equilibrium Analysis: Implementation in the Interactive Program STANJAN," Technical Rept., Mechanical Engineering Dept., Stanford Univ., Stanford, CA, Jan. 1986.

${ }^{55}$ Wintenberger, E., Austin, J. M., Cooper, M., Jackson, S., and Shepherd, J. E., "Impulse of a Single-Pulse Detonation Tube," Technical Rept., FM00-8, Graduate Aeronautical Labs., California Inst. of Technology, Pasadena, CA, Aug. 2002.

${ }^{56}$ Cooper, M., and Shepherd, J. E., "Effect of a Porous Thrust Surface on Detonation Transition and Detonation Tube Impulse," Journal of Propulsion and Power, Vol. 20, No. 5, 2004, pp. 811-819.

${ }^{57}$ Austin, J. M., and Shepherd, J. E., "Detonations in Hydrocarbon Fuel Blends," Combustion and Flame, Vol. 132, Jan. 2003, pp. 73-90.

${ }^{58}$ Papavassiliou, J., Makris, A., Knystautas, R., Lee, J. H. S., Westbrook, C. K., and Pitz, W. J., "Measurements of Cellular Structure in Spray Detonation," Progress in Aeronautics and Astronautics, Vol. 154, 1993, pp. $148-169$.

${ }^{59}$ Cooper, M., "Impulse Generation by Detonation Tubes," Ph.D. Dissertation, Graduate Aeronautical Laboratories at the California Institute of Technology, California Inst. of Technology, Pasadena, CA, June 2004.

${ }^{60}$ Morris, C., "Axisymmetric Modeling of Pulse Detonation Rocket Engines," AIAA Paper 2005-3508, July 2005.

${ }^{61}$ Kailasanath, K., "A Review of Research on Pulse Detonation Engine Nozzles,” AIAA Paper 2001-3932, July 2001. 